\title{
Consolidation and challenges
}

\section{Editorial}

Now that the Sociology International Journal (SIJ) has entered its third year of publication, and having the honour of serving as Editor-in-Chief since October 9, 2018, I believe the time has come to share some considerations, on the one hand, about the consolidation attained and, on the other hand, regarding the challenges to be faced (and overcome) in the near future by SIJ.

Notwithstanding being still a relatively young journal, SIJ is in its third volume, Issue 1, having published in Volume 1 four numbers with 21 publications, and in Volume 2 six numbers with 107 publications of the most diverse types (such as Opinion, Short Communication, Mini Review, Review, Research Article, and Editorial). A brief analysis allows observing that there is a great variety in terms of the institutional origin and authors' countries, with a multiplicity of topics addressed.

As dialogue between different scientific areas is critical, ${ }^{1}$ even within the Sociology field itself (Serpa, 2018a), and especially in an increasingly digital ${ }^{2}$ and innovative society, ${ }^{3}$ two Special Issues were also published, one dedicated to "Political Science and International" (with six papers), and another one on "Business Economics" (with four papers). This summary on SIJ publications allows concluding that this journal is fulfilling its mission, which, I remind, is to spread "the research articles and theoretical essays by social scientists from around the world, providing insight into the issues facing by the society as well as social and cultural systems in other countries. This journal presents path breaking work from all areas of sociology, including anthropology, criminology, philosophy, education, gender, medicine and organization with significance on theory building and innovative methods. SIJ strives to articulate with the sociological researchers and is open to receive contributions from anthropologists, statisticians, economists, educators, historians and political scientists".

Sociological reflection, ${ }^{4}$ to which SIJ seeks to be an input, is decisive for its contribution in understanding a social reality that is always complex and in permanent mutation:2,4,5,6 "Sociology, as a privileged scientific space for (self)reflection on its own activity and the resulting product, contributes to a specialised knowledge with the limitations that this entails; thus, it is important, on the one hand, to foster a sociological perspective that spurs, in the process of construction and analysis of its objects, the influence of cultural, economic, and political aspects, and, on the other hand, which encourages the dialogue with other disciplinary and scientific spaces".

This very brief analysis allows considering that SIJ consolidation is happening with positive results but, as a never-finished process, compels all those who are connected to this Journal (Editorial Board, Reviewers, Publisher, Office Team), to whom I take the chance to thank for their cooperation, to continue their work with the same persistence, to increase its scientific reputation and credibility. Regarding the challenges to overcome, the aforementioned SIJ consolidation emerges as an opportunity, by creating better conditions to increase its scientific recognition and knowledge. In this sense, the work of indexing the journal in databases of peer-reviewed scientific literature of acknowledged excellence will continue, maintaining the rigour and the high standards, both in the evaluation of the submitted manuscripts (through a critical assessment that is intended to be constructive for
Volume 3 Issue I - 2019

\author{
Sandro Serpa \\ Department of sociology, University of the Azores, Portugal
}

Correspondence: Sandro Serpa, University of the Azores, Faculty of Social and Human Sciences, Department of Sociology, Interdisciplinary Centre of Social Sciences - CICS.UAc/ CICS.NOVA.UAc, Interdisciplinary Centre for Childhood and Adolescence-NICA-UAc, Ponta Delgada, Portugal,Tel 351964424554,Email sandro.nf.serpa@uac.pt

Received: January 15, 2019 | Published: January 21, 2019

the collaboration in the improvement of the manuscript) and in the quality of the publication of accepted manuscripts.

Other challenges to SIJ emerge from the context of scientific publications, which is in permanent simmering with the inevitability of the increasing weight of open access. ${ }^{7}$ This has always been a feature of SIJ, as well as, among others, the possibility of implementing various forms of evaluation of the submitted manuscripts, ${ }^{8}$ the emergence of the preprint publication, with a growing acceptance in the social sciences field, with its potential advantages and limitations, ${ }^{9}$ and the place and influence of social networks on scientific dissemination. ${ }^{10}$

In summary, this is SIJ's situation, and we seek to be prepared to give a positive answer that respects the two principles that seem to me to be central and guiding of the prolific existence of SIJ as a scientific journal and that must be permanently fostered: quality and democraticity, which must work in close articulation, from the submission of manuscripts, their evaluation, subsequent publication and, as a corollary, to serve and to earn the trust of the readers themselves. ${ }^{11-14}$

I wish all those who follow our journal excellent sociological cogitations.

\section{Acknowledgments}

None.

\section{Funding}

University of the Azores, Interdisciplinary Centre of Social Sciences-CICS.UAc/CICS.NOVA.UAc, UID/SOC/04647/2013, with the financial support of the FCT/MEC through national funds and when applicable co-financing from the FEDER under the PT2020 Partnership Agreement."

\section{Conflicts of interest}

The author declares that there are no conflicts of interest.

\section{References}

1. Serpa S, Ferreira CM, Santos AI. Fostering interdisciplinarity: Implications for social sciences. International Journal of Social Science Studies. 2017;5(12):44-49.

2. Ferreira CM, Serpa S. Society 5.0 and social development: Contributions to a discussion. Management and Organizational Studies. 2018a;5(4):26-31.

3. González PF Coord, Garrão AP, Diogo F, et al. Intervenção e novas 
realidades sociais-Atas IX Encontro Internacional de Inovação Educacional. Ponta Delgada: University of the Azores; 2018.

4. Serpa S, Ferreira CM. Anomie in the sociological perspective of Émile Durkheim. Sociol Int J. 2018b;2(6):689-691.

5. Ferreira CM, Serpa S. Challenges in the teaching of sociology in higher education. Contributions to a discussion. Societies-Special Issue Training Models and Practices in Sociology. 2017;7(4):1-11.

6. Serpa S, Sá MJ. Exploring Sociology of Education in the promotion of sustainability literacy in higher education. Preprints. 2018;1: 2018100614

7. The European Research Council. Main changes expected in the ERC Work Programme 2019. 2019. 19 p.

8. Ferreira CM, Serpa S. Publicising the identified Peer-Reviewer: Legitimacy and quality of the scientific publication. The International Journal of Interdisciplinary Educational Studies. 2018b;13(1):11-17.
9. Ferreira CM, Serpa S. The Importance of preprint in scientific publication: Perspectives and challenges. The Journal of Social Sciences Research. 2018c;4(12):642-647.

10. Ferreira CM, Serpa S. Online visibility, social networks and glamorous scientific publications. International Journal of Social Science Studies. 2018d;6(10):58-66.

11. Serpa S. Quality and democraticity in scientific dissemination. Sociol Int J. 2018c;2(5):429.

12. Serpa S. A reflection on Sociology of Education. International Journal of Social Science Studies. 2018a;6(3):33-39.

13. Serpa S. Reflexivity in Sociology. Sociol Int J. 2018b;2(6):584.

14. Serpa S, Ferreira CM. Sociological problem and social problem: Contributions to a discussion. Sociology and Anthropology. 2018a;6(11):840-844. 